
\title{
25 Research Square \\ Clinical Predictors of Lung Function in Patients Recovering from Mild COVID-19
}

\section{Arturo Cortes-Telles ( $\nabla$ dr_morenheim@hotmail.com )}

Hospital Regional de Alta Especialidad de la Peninsula de Yucatan. Yucatan

\section{Esperanza Figueroa-Hurtado}

Hospital Regional de Alta Especialidad de la Peninsula de Yucatan. Yucatan

\section{Diana Lizbeth Ortiz-Farias}

Hospital Regional de Alta Especialidad de la Peninsula de Yucatan. Yucatan

\section{Gerald Stanley Zavorsky}

UC Davis Medical Center

\section{Research Article}

Keywords: respiratory function test, SARS-CoV-2, Mexico, DLCO, lung.

Posted Date: December 10th, 2021

DOI: https://doi.org/10.21203/rs.3.rs-1124510/v1

License: (c) (i) This work is licensed under a Creative Commons Attribution 4.0 International License. Read Full License 


\section{Abstract}

Background: There are few studies have assessed lung function in Hispanic subjects recovering from mild COVID-19. Therefore, we examined the prevalence of impaired pulmonary diffusing capacity for carbon monoxide (DLCO) as defined by values below the lower limit of normal ( $<L L N,<5^{\text {th }}$ percentile) in Hispanics recovering from mild COVID-19. We also examined the prevalence of a restrictive spirometric pattern as defined by the ratio of forced expiratory volume in $1 \mathrm{~s}\left(\mathrm{FEV}_{1}\right)$ to forced vital capacity (FVC) being $\geq$ LLN with the FVC being < LLN. Finally, we wanted to examine factors that cause the prevalence of an impaired DLCO to vary between studies.

Methods: In this observational study, adult patients $(n=146)$ with mild COVID-19 were recruited from a Long-term follow-up COVID-19 clinic in Yucatan, Mexico between March, and August 2021. Spirometry, DLCO, and self-reported signs/symptoms were recorded $34 \pm 4$ days after diagnosis.

Results: At post-evaluation, $20 \%$ and $30 \%$ patients recovering from COVID-19 were classified as having a restrictive spirometric pattern and impaired DLCO, respectively; $13 \%$ had both. The most prevalent reported symptoms were fatigue (73\%), persistent cough (43\%), shortness of breath (42\%) and a blocked/runny nose (36\%). Increased age, a blocked/runny nose, excessive night sweats, and a restrictive spirometric pattern increased probability of having an impaired DLCO. The proportion of patients with previous mild COVID-19 who had impaired DLCO increased by $12 \%$ when the definition of impaired DLCO was $<80 \%$ predicted instead of $<$ LLN. Having severe (compared to mild) COVID-19 increased the percentage of those with impaired DLCO by $20 \%$.

Conclusions: One-third of patients with mild COVID-19 have impaired DLCO thirty-four days postdiagnosis. One-fifth of patients have a restrictive spirometric pattern. The criteria that define impaired DLCO and the severity of COVID-19 disease affects the proportion of those with impaired DLCO at followup.

\section{Introduction}

Severe acute respiratory syndrome coronavirus 2 (SARS-CoV2) is a virus that originated in Wuhan City, China, in December of 2019, and is responsible for the coronavirus disease (COVID-19) [1]. Between December $29^{\text {th }}, 2019$, and February $16^{\text {th }}, 2020$, the number of deaths increased from 1 to 1666 in China. ${ }^{1}$ By October $1^{\text {st }}, 2021$, over 4.79 million people worldwide has died from COVID-19 [2]. As such, COVID-19 has become one of the most fatal pandemics ever recorded in human history.

COVID-19 is a heterogenous disease, with several long-term sequelae [3]. Patients recovering from the acute phase may report long-term multi-system symptoms including various pulmonary function abnormalities [3-22], psychological sequelae [3], and reduced physical functioning [10,23,24]. Specifically, pulmonary diffusing capacity for carbon monoxide (DLCO) has been shown to be significantly impaired 30 to 180 days after the onset of onset of (SARS-CoV-2) (Table S1). However, most of these studies 
evaluated lung function in patients that were hospitalised due to the severity of their condition; very few studies focused on patients recovering from mild COVID-19 [4,7,10,20]. Furthermore, there are even fewer studies focusing on the effects of COVID-19 in Latino populations [6,25]. As the number of patients recovering from COVID-19 increases around the world, there is an urgent need to keep analysing pulmonary sequelae to facilitate optimal clinical treatments.

Recent reports indicate the presence of racial and ethnic disparities with disproportionate burden of COVID-19-related severity infections and mortality $[26,27]$. These disparities may be at least partly attributable to the higher rates of comorbidities that worsen COVID-19 outcomes [28]. Mexico has a high prevalence of chronic non-communicable diseases such as obesity, hypertension, and diabetes; also, pandemic data after acute COVID-19 about Latinos has been severely limited due to categorizations, language and other research barriers, therefore, very few descriptions have analyzed physiological explanations on persistent symptoms and lung function in the Latino community [28].

Our main objective was to determine factors associated with an impaired DLCO in Hispanic patients with mild COVID-19. Impaired DLCO was defined as a low pulmonary diffusing capacity for carbon monoxide (DLCO) that was below the lower limit of normal ( $<L L N,<5^{\text {th }}$ percentile). Another objective was to examinee data from previous studies to determine which factors predicted the proportion of patients who had both previous COVID-19 disease and impaired DLCO at follow-up.

\section{Materials And Methods}

\section{Study design}

This is an observational cross-sectional study from the Long-term follow-up COVID-19 clinic at the High Specialty Regional Hospital of Yucatan, Mexico from March 2021 to August 2021. We consecutively enrolled one hundred and fifty patients during the period. Inclusion criteria were adults over 18 years old recovering from mild COVID-19 according to current WHO diagnostic criteria [29]. All patients were scheduled after 4-6 weeks (34.4 \pm 3.8 days) of baseline symptoms to perform pulmonary function test and were evaluated for persistent symptoms at the clinic. Ethics approval was obtained from the Ethics Committee of the High Specialty Regional Hospital in Yucatan, Mexico (Protocol number 2020-024). A written informed consent to participate was signed by all patients at the scheduled visit in compliance with the Helsinki declaration. This study followed the Strengthening the Reporting of Observational Studies in Epidemiology (STROBE) reporting guideline.

\section{Methods}

Patients received a comprehensive medical assessment with a detailed medical history. Data including demographics, persistent symptoms from surveys, and pulmonary function test results were collected during the follow-up visit. Demographic data included age, sex, body mass index (BMI), and previous cardiovascular disease risk factors for which regular pharmacological treatment was incorporated including systemic hypertension, cardiac disease, diabetes mellitus, Tobacco use (current or former 
smoker vs. never smoker), obesity (defined as body mass index $>30 \mathrm{~kg} / \mathrm{m}^{2}$ ). Patients were asked if they received oral corticosteroids and/or anticoagulants during the disease and to recount presence or absence of symptoms at the time of the visit including: fatigue, shortness of breath on effort, cough, chest tightness, chest pain, sore throat, blocked and/or runny nose, loss of smell, loss of taste, diarrhea, abdominal pain, muscle or joint pain, headache, tachycardia, sore or red eyes, excessive sweating (over a $24 \mathrm{hr}$ period, including night sweats), hair loss, and weight loss [30,31].

Spirometry and measurements of DLCO, were performed approximately four weeks following baseline symptoms through standard equipment (Easy One $\mathrm{Pro}^{\circ}$, NDD Medical Technologies, Switzerland). Spirometry reference equations were obtained from Hankinson (1999) [32]. The technical quality of spirometry was adhered to per 2019 spirometry standards [33]. The reference equations for pulmonary diffusing capacity for carbon monoxide (DLCO) was obtained from Vazquez-Garcia and colleagues [32]. The 2017 Technical standards for DLCO were followed for technical quality [34].

\section{Analysis}

A Fisher's exact test compared the number males versus females being below the LLN for DLCO. A Fisher's exact test also compared the number males versus females with a restrictive spirometric pattern as defined by the ratio of forced expiratory volume in $1 \mathrm{~s}\left(\mathrm{FEV}_{1}\right)$ to forced vital capacity (FVC) being $\geq$ LLN with the FVC being less than the LLN. The Fisher's Exact Test would allow an examination of a sex differences in the proportion of males versus females that had abnormally low lung function. Several $\mathrm{N}-1$ Chi-Squared Tests were used to determine whether the percentage of several signs and symptoms that were present post-COVID-19 were different between those with a DLCO $<$ LLN and those with a DLCO $\geq$ LLN [35]. A Benjamini-Hochberg procedure was used to control the false discovery rate [36], which we set to 0.05 .

Binary logistic regression was performed using the Forward: Likelihood ratio method (enters independent variables one at a time) to determine the factors associated with an impaired DLCO (DLCO < LLN) in the mild post-COVID-19 patients. Cardiovascular disease (CVD) risk factors [smoking status (yes, no), high blood pressure (yes, no), cardiac arrhythmia (yes, no), obesity (yes, no)], true cardiac disease (yes, no), fatigue, dyspnoea, cough, headache, chest tightness, sore throat, persistent loss of smell (yes, no), dysfunction in the sense of taste (yes, no), conjunctivitis, blocked and/or runny nose, use of oral corticosteroids during the disease (yes, no), use of anticoagulant medications (yes, no), sex (male, female), age in z scores, height in z scores, weight in z scores, body mass index (BMI) in z scores, a restrictive spirometric pattern (forced vital capacity or FVC below the lower limit of normal, LLN, and $\left.\mathrm{FEV}_{1} / \mathrm{FVC} \geq \mathrm{LLN}\right)$, forced expiratory volume in $1 \mathrm{~s}\left(\mathrm{FEV}_{1}\right)(\mathrm{y}=$ yes, $0=$ no), forced expiratory flow rate over the middle half of expiration $\left(\mathrm{FEF}_{25-75}\right)$ in $\mathrm{z}$ scores and peak expiratory flow (PEF) in z scores.

Using mean data from22 previous studies (including the current study), multiple linear regression analysis using forward selection was used to identify which of the five following factors would predict the proportion of patients who had previous COVID-19 and impaired DLCO at follow-up. The mean age 
(years), mean body mass index $\left(\mathrm{kg} / \mathrm{m}^{2}\right)$, mean number of days between receiving the COVID-19 diagnosis and follow-up, history of mild vs severe COVID-19 disease (i.e. patients that were either hospitalized, intubated, presented with fibrotic CT changes in the lung were labelled as 1 , compared to those that were not labelled as 0 ), and the criteria used to define impaired DLCO (DLCO $<80 \%$ predicted labelled as 1 , vs DLCO < LLN labelled as 0 ) were predictors used in the model.

All data were analysed by a statistical software package (IBM SPSS Statistics, Version 27, Chicago IL). A $p$-value of $<0.05$ was used to signify statistical significance. Any case with a studentized residual $\geq 3.0$ were removed from any model.

\section{Results}

One hundred and fifty subjects were recruited from the Long-term follow-up COVID-19 clinic. Four patients were removed due to the reference equations not fitting the age range of the subjects, leaving 146 patients for the analysis. The anthropometric characteristics are presented in Table 1. Approximately, 50\% of the subjects were obese (BMI $\left.\geq 30 \mathrm{~kg} / \mathrm{m}^{2}\right)$. The gas exchange parameter, DLCO, was significantly reduced compared to predicted values (Table 2). In fact, $30 \%$ of the sample had a DLCO value that was below the LLN, and the percentages were similar between males and females (Table 3). Twenty-one percent of the sample had a restrictive spirometric pattern (FVC $<L L N$ and an $F_{1} V_{1} / F V C \geq L L N$ ) (Table 3) and when coupled with an DLCO $<$ LLN, about $13 \%$ of the patients had both impaired DLCO and lung restriction.

For the regression analysis, two subjects had missing data, so 144 subjects were used. The binary logistic regression revealed an overall model of four predictors that was statistically reliable in distinguishing between those with a DLCO below the LLN and those with normal DLCO [-2 Log Likelihood $=131.7$, Cox \& Snell $\mathrm{R}^{2}=0.26$, Nagelkerke $\mathrm{R}^{2}=0.38$; Omnibus tests of model coefficients $\chi^{2}=43.9, \mathrm{~d} f=4$, $p=0.000]$. Increased age, a blocked/ runny nose, excessive sweating, and a restrictive spirometric pattern increased the probability of having an impaired DLCO. The model was a good fit [Hosmer and Lemeshow Test, $\left.\chi^{2}=2.44, \mathrm{df}=8, p=0.96\right]$, correctly identifying $77 \%$ of the cases (Table 4).

Using mean data from22 previous studies (including the current study, see Table S1), multiple linear regression analysis was used to identify which factors would predict the proportion of previously infected SARS-CoV-2 patients with impaired DLCO at follow-up. Regression results indicate an overall model of three predictors (previous history of severe COVID-19, criteria used to define impaired DLCO, and mean age of the group) that significantly determined the percentage of previously infected COVID-19 patients with an impaired DLCO at follow-up $\left[\mathrm{R}^{2}{ }_{\text {adj }}=0.37, \mathrm{~F}(3,34)=8.24, p=0.0003\right]$. The model accounted for $37 \%$ of the variance defining those with DLCO impairment. A summary of the regression model is presented in Table 5. Having a previous severe case of COVID-19 increases the proportion of those with impaired DLCO by $20 \%$ at follow-up. As well, when using the more liberal definition of impaired DLCO (< $80 \%$ of predicted), the proportion of those with impaired DLCO increased by $12 \%$ in a given study. Finally, when the mean age for each study increased by 1 year in age (from 41 to 69 years), the proportion of 
those with impaired DLCO increased by about 4\%. Interestingly, the time of follow-up (20 to 180 days) did not seem to affect the percentage of those with impaired DLCO in a particular study.

\section{Discussion}

A main purpose of this study was to identify possible predictors of impaired DLCO in patients that had mild COVID-19 within the first 4 to 6 weeks. We found that patients who are recovering from mild COVID19 also have persistent symptoms (Table S2) as well as pulmonary function abnormalities (Table 3). For each one standard deviation unit increase in age (which approximates 13 years), the odds of having an impaired DLCO increased by nearly 3-fold, while having a restrictive spirometric pattern increased the risk of having an impaired DLCO by almost 7-fold (Table 4). Regarding symptoms, having reported a blocked/runny nose and excessive sweating at follow up also increased the odds of having an impaired DLCO by about 3 to 4 -fold, each (Table 4). When using the logistic model, using a mean age of 50.6 years ( $z$ score $=0$ ), having no lung restriction $(0)$, no blocked nose $(0)$ and no excessive night sweats $(0)$, the probability of an impaired DLCO in this population is $8 \%$. The probability increases to $36 \%$ when a restrictive spirometric pattern is evident (Table 4). Thus, having a restrictive spirometric pattern increases the odds of having impaired DLCO at follow-up. While $20 \%$ percent of the patients had a restrictive spirometric pattern, only $3 \%$ of patients showed an obstructive pattern (as defined by a $\mathrm{FEV}_{1} / \mathrm{FVC}$ below LLN), which demonstrates that the after-effects COVID-19 are likely to result in lung restriction and poor pulmonary diffusion.

Another purpose of this study was to determine the variables that predict the percentage of previously infected SARS-CoV-2 patients who had a DLCO impairment during follow-up. Having severe COVID-19 disease at diagnosis, increased the percentage of those with impaired DLCO by nearly $20 \%$. If the study used the usual cutoff $<80 \%$ of predicted to define DLCO impairment, then $12 \%$ more patients would be classified as having abnormal gas exchange. Thus, if using the stricter definition of DLCO impairment as being below the LLN (i.e., below the 5th percentile) for height, age, sex, and ethnicity, then $12 \%$ few patients would be classified as having a reduced DLCO. The definition of a low DLCO being < $80 \%$ of predicted is not correct and may misclassify patients, as the percent of the predicted value at the LLN (5 ${ }^{\text {th }}$ percentile) decreases beginning at about 40 years of age. [37,38] Patients who have the same height, sex, and ethnicity have a DLCO that is about $79 \%$ of predicted at 40 years of age at the LLN ( $5^{\text {th }}$ percentile) compared to about $73 \%$ of predicted at 85 years of age at the LLN [38]. Therefore, using zscores are more correct to use instead of using absolute cutoff $<80 \%$ predicted to define a clinically low DLCO.

We were not able to measure total lung capacity (TLC) using a body plethysmograph to verify lung restriction, thus a restrictive spirometric pattern $\left(\mathrm{FEV}_{1} / \mathrm{FVC} \geq \mathrm{LLN}\right.$ and $\mathrm{FVC}<\mathrm{LLN}$, pre-bronchodilator) was used instead as a surrogate of true lung restriction. The sensitivity to identify true pulmonary restriction (TLC < LLN) with a restrictive spirometric pattern is about $34 \%$ but the specificity is nearly $98 \%$ [39]. The negative predictive value (NPV), meaning that the percentage of patients who do not have a restrictive spirometric pattern and whom do not have restrictive lung disease is $97 \%$ [39]. The prevalence 
of a restrictive spirometric pattern ( $\mathrm{FEV}_{1} / \mathrm{FVC} \geq \mathrm{LLN}$ and $\mathrm{FVC}<\mathrm{LLN}$, pre-bronchodilator) in populations is about 3 to $9 \%[39,40]$. In this group of patients that had mild COVID-19, we found that the restrictive spirometric pattern to be about $20 \%$ which is more than double the population average.

Among persistent symptoms, fatigue, shortness of breath on effort are the most prevalent descriptors included in Long COVID-19 and these were not different in ambulatory patients recovering from mild COVID-19 [30]. About 74\% of the patients experienced undue fatigue and nearly half experienced shortness of breath on effort and / or a significant cough.

\section{Limitations}

Our study has some limitations. In addition to not having measured lung volumes with plethysmography, we do not have any baseline lung function data in these patients prior to SARS-CoV-2 infection as well as a control group, due to the pandemic, to perform further analysis. However, mostly all studies involving lung function analysis among COVID-19 survivors were done with the same limitation. Indeed, it is difficult to determine with certainty that these patients with poor diffusing capacity and/or a restrictive spirometric pattern is due to them having mild COVID-19. Nonetheless, these patients are compared against established reference norms and the prevalence of an impaired DLCO in our sample was fivetimes more than expected in a normal population and at least two-fold more than expected for a restrictive spirometric pattern. To reduce this bias, we analysed all risk factors related with lung function abnormalities including published studies. Also, there is gap in implementing regular lung function assessment in case of suspected obstructive lung disease, instead chest x-ray studies are more frequently requested, especially in countries with limited-resource settings, therefore it is expected that patients were not subjected to pulmonary function tests prior to SARS-CoV-2 infection.

\section{Conclusion}

Nearly one-third of patients with mild COVID-19 have impaired DLCO 34 days post-diagnosis and one-fifth of patients have lung restriction. The odds of having an impaired DLCO at follow-up increased nearly 7fold if a restrictive spirometric pattern was evident. Increased age, having excessive night sweats, and a blocked/runny nose also increased the probability of an impaired DLCO at follow-up. In a summary of 22 studies, having severe COVID-19 disease at diagnosis increased the percentage of those with impaired DLCO by nearly $20 \%$. And, if the study used $<80 \%$ of predicted to define DLCO impairment, then $12 \%$ more patients would be classified as having poor gas exchange.

\section{Declarations}

\section{Ethics approval and consent to participate}

- Ethics approval was obtained from the Ethics Committee of the High Specialty Regional Hospital in Yucatan, Mexico (No. CONBIOETICA-31-CEI-002-20170731)

- The Ethics Committee assigned the Protocol number 2020-024. 
- A written informed consent to participate was signed by all patients at the scheduled visit in compliance with the Helsinki declaration.

\section{-Consent for publication}

- Not applicable.

\section{-Availability of data and material}

- All data generated or analyzed during this study are included in this article and/or its supplementary material files. Further enquiries can be directed to the corresponding author.

\section{•Funding}

- None.

\section{-Competing interests}

- The authors declare that they have no competing interests.

\section{-Authors' contributions}

- Arturo Cortes-Telles, Esperanza Figueroa-Hurtado, Diana Lizbeth Ortiz-Farias, Gerald Stanley Zavorsky designed the study.

- Arturo Cortes-Telles, Esperanza Figueroa-Hurtado, Diana Lizbeth Ortiz-Farias collected the data.

- Arturo Cortes-Telles and Gerald Stanley Zavorsky analyzed the data and prepared the manuscript.

- Arturo Cortes-Telles, Esperanza Figueroa-Hurtado, Diana Lizbeth Ortiz-Farias, Gerald Stanley Zavorsky made critical revisions to the manuscript and approved the final version.

\section{-Acknowledgements}

- Not applicable.

\section{References}

1. Rothan HA, Byrareddy SN. The epidemiology and pathogenesis of coronavirus disease (COVID-19) outbreak. J. Autoimmun. 2020;109:102433. doi: 10.1016/j.jaut.2020.102433.

2. Our World in Data. Cumulative COVID-19 tests, confirmed cases and deaths, world Global Change Data Lab; 2021 [cited 2021 October 2nd.]. Available from: https://ourworldindata.org/grapher/covid-testscases-deaths?country= OWID_WRL. 
3. Bellan M, Soddu D, Balbo PE, Baricich A, Zeppegno P, Avanzi GC, et al. Respiratory and Psychophysical Sequelae Among Patients With COVID-19 Four Months After Hospital Discharge. JAMA Netw Open. 2021;4(1):e2036142. doi: 10.1001/jamanetworkopen.2020.36142.

4. Abdallah SJ, Voduc N, Corrales-Medina VF, McGuinty M, Pratt A, Chopra A, et al. Symptoms, Pulmonary Function and Functional Capacity Four Months after COVID-19. Ann Am Thorac Soc. 2021. Apr 19. doi: 10.1513/AnnalsATS.202012-1489RL. Online ahead of print.

5. Morin L, Savale L, Pham T, Colle R, Figueiredo S, Harrois A, et al. Writing Committee for the Comebac Study Group. Four-Month Clinical Status of a Cohort of Patients After Hospitalization for COVID19. JAMA. 2021;325(15):1525-34. doi: 10.1001/jama.2021.3331.

6. Gochicoa-Rangel L, Hernandez-Morales AP, Salles-Rojas A, Madrid-Mejia W, Guzman-Valderrabano C, Gonzalez-Molina A, et al. Gas Exchange Impairment During COVID-19 Recovery. Respir Care. 2021;66(10):1610-17. doi: 10.4187/respcare.09114.

7. Barisione G, Brusasco V. Lung diffusing capacity for nitric oxide and carbon monoxide following mildto-severe COVID-19. Physiol Rep. 2021;9(4):e14748. doi: 10.14814/phy2.14748.

8. Ekbom E, Frithiof R, Emilsson O, Larson LM, Lipcsey M, Rubertsson S, et al. Impaired diffusing capacity for carbon monoxide is common in critically ill Covid-19 patients at four months post-discharge. Respir Med. 2021;182:106394. doi: 10.1016/j.rmed.2021.106394.

9. Nunez-Fernandez M, Ramos-Hernandez C, Garcia-Rio F, Torres-Duran M, Nodar-Germinas A, TilveGomez A, et al. Alterations in Respiratory Function Test Three Months after Hospitalisation for COVID-19 Pneumonia: Value of Determining Nitric Oxide Diffusion. J Clin Med. 2021;10(10):2119. doi: 10.3390/jcm10102119.

10. van den Borst B, Peters JB, Brink M, Schoon Y, Bleeker-Rovers CP, Schers H, et al. Comprehensive Health Assessment 3 Months After Recovery From Acute Coronavirus Disease 2019 (COVID-19). Clin Infect Dis. 2021;73(5):e1089-e98. doi: 10.1093/cid/ciaa1750.

11. Lerum TV, Aalokken TM, Bronstad E, Aarli B, Ikdahl E, Lund KMA, et al. Dyspnoea, lung function and CT findings 3 months after hospital admission for COVID-19. Eur Respir J. 2021;57(4):2003448. doi: 10.1183/13993003.03448-2020.

12. Guler SA, Ebner L, Aubry-Beigelman C, Bridevaux PO, Brutsche M, Clarenbach C, et al. Pulmonary function and radiological features 4 months after COVID-19: first results from the national prospective observational Swiss COVID-19 lung study. Eur Respir J. 2021;57(4):2003690. doi:

10.1183/13993003.03690-2020.

13. Han X, Fan Y, Alwalid O, Li N, Jia X, Yuan M, et al. Six-month Follow-up Chest CT Findings after Severe COVID-19 Pneumonia. Radiology. 2021;299(1):E177-E86. doi: 10.1148/radiol.2021203153. 
14. Sonnweber T, Sahanic S, Pizzini A, Luger A, Schwabl C, Sonnweber B, et al. Cardiopulmonary recovery after COVID-19: an observational prospective multicentre trial. Eur Respir J. 2021;57(4):2003481. doi: 10.1183/13993003.03481-2020.

15. Blanco JR, Cobos-Ceballos MJ, Navarro F, Sanjoaquin I, Arnaiz de Las Revillas F, Bernal E, et al. Pulmonary long-term consequences of COVID-19 infections after hospital discharge. Clin Microbiol Infect. 2021;27(6):892-6. doi: 10.1016/j.cmi.2021.02.019.

16. Qin W, Chen S, Zhang Y, Dong F, Zhang Z, Hu B, et al. Diffusion capacity abnormalities for carbon monoxide in patients with COVID-19 at 3-month follow-up. Eur Respir J. 2021;58(1):2003677. doi: 10.1183/13993003.03677-2020.

17. Shah AS, Wong AW, Hague CJ, Murphy DT, Johnston JC, Ryerson CJ, et al. A prospective study of 12week respiratory outcomes in COVID-19-related hospitalisations. Thorax. 2021;76(4):402-4. doi: 10.1136/thoraxjnl-2020-216308.

18. Huang Y, Tan C, Wu J, Chen M, Wang Z, Luo L, et al. Impact of coronavirus disease 2019 on pulmonary function in early convalescence phase. Respir Res. 2020;21(1):163. doi: 10.1186/s12931-02001429-6.

19. Liang L, Yang B, Jiang N, Fu W, He X, Zhou Y, et al. Three-month Follow-up Study of Survivors of Coronavirus Disease 2019 after Discharge. J Korean Med Sci. 2020;35(47):e418. doi: 10.3346/jkms.2020.35.e418.

20. Mo X, Jian W, Su Z, Chen M, Peng H, Peng P, et al. Abnormal pulmonary function in COVID-19 patients at time of hospital discharge. Eur Respir J. 2020;55(6):2001217. doi: 10.1183/13993003.01217-2020.

21. Liu K, Zhang W, Yang Y, Zhang J, Li Y, Chen Y. Respiratory rehabilitation in elderly patients with COVID19: A randomized controlled study. Complement Ther Clin Pract. 2020;39:101166. doi: 10.1016/j.ctcp.2020.101166.

22. Zhao YM, Shang YM, Song WB, Li QQ, Xie H, Xu QF, et al. Follow-up study of the pulmonary function and related physiological characteristics of COVID-19 survivors three months after recovery. EClinicalMedicine. 2020;25:100463. doi: 10.1016/j.eclinm.2020.100463.

23. Baricich A, Borg MB, Cuneo D, Cadario E, Azzolina D, Balbo PE, et al. Midterm functional sequelae and implications in rehabilitation after COVID-19: a cross-sectional study. Eur J Phys Rehabil Med. 2021; 57(2): 199-207. doi: 10.23736/S1973-9087.21.06699-5.

24. van der Sar-van der Brugge S, Talman S, Boonman-de Winter L, de Mol M, Hoefman E, van Etten RW, et al. Pulmonary function and health-related quality of life after COVID-19 pneumonia. Respir Med. 2021;176:106272. doi: 10.1016/j.rmed.2020.106272. 
25. Cortes-Telles A, Lopez-Romero S, Figueroa-Hurtado E, Pou-Aguilar YN, Wong AW, Milne KM, et al. Pulmonary function and functional capacity in COVID-19 survivors with persistent dyspnoea. Respir Physiol Neurobiol. 2021;288:103644. doi: 10.1016/j.resp.2021.103644.

26. Buikema AR, Buzinec P, Paudel ML, Andrade K, Johnson JC, Edmonds YM, et al. Racial and ethnic disparity in clinical outcomes among patients with confirmed COVID-19 infection in a large US electronic health record database. EClinicalMedicine. 2021;39:101075. doi: 10.1016/j.eclinm.2021.101075.

27. St Sauver JL, Lopes GS, Rocca WA, Prasad K, Majerus MR, Limper AH, et al. Factors Associated With Severe COVID-19 Infection Among Persons of Different Ages Living in a Defined Midwestern US Population. Mayo Clin Proc. 2021;96:2528-39. doi: 10.1016/j.mayocp.2021.06.023.

28. Parra-Rodriguez L, Gonzalez-Meljem JM, Gomez-Dantes H, Gutierrez-Robledo LM, Lopez-Ortega M, Garcia-Pena C, et al. The Burden of Disease in Mexican Older Adults: Premature Mortality Challenging a Limited-Resource Health System. J Aging Health. 2020;32(7-8):543-53. doi:

$10.1177 / 0898264319836514$.

29. Geneva: WHO. COVID-19 Clinical management: living guidance. Available from: https://www.who.int/publications/i/item/WHO-2019-nCoV-clinical-2021-1. Date last accessed: October $11,2021$.

30. Lopez-Leon S, Wegman-Ostrosky T, Perelman C, Sepulveda R, Rebolledo PA, Cuapio A, et al. More than 50 long-term effects of COVID-19: a systematic review and meta-analysis. Sci Rep. 2021;11(1):16144. doi: 10.1038/s41598-021-95565-8.

31. Elliott J, Whitaker M, Bodinier B, Eales O, Riley S, Ward H, et al. Predictive symptoms for COVID-19 in the community: REACT-1 study of over 1 million people. PLoS. Med. 2021;18(9):e1003777. doi: 10.1371/journal.pmed.1003777.

32. Vazquez-Garcia JC, Perez-Padilla R, Casas A, Schonffeldt-Guerrero P, Pereira J, Vargas-Dominguez C, et al. Reference values for the diffusing capacity determined by the single-breath technique at different altitudes: The Latin American single-breath diffusing capacity reference project. Respir Care. 2016;61(9):1217-23. doi: 10.4187/respcare.04590.

33. Graham BL, Steenbruggen I, Miller MR, Barjaktarevic IZ, Cooper BG, Hall GL, et al. Standardization of Spirometry 2019 Update. An Official American Thoracic Society and European Respiratory Society Technical Statement. Am J Respir Crit Care Med. 2019;200(8):e70-e88. doi: 10.1164/rccm.201908$1590 \mathrm{ST}$.

34. Graham BL, Brusasco V, Burgos F, Cooper BG, Jensen R, Kendrick A, et al. 2017 ERS/ATS standards for single-breath carbon monoxide uptake in the lung. Eur Respir J. 2017;49(1):1600016. doi: 10.1183/13993003.00016-2016. 
35. Campbell I. Chi-squared and Fisher-Irwin tests of two-by-two tables with small sample recommendations. Stat Med. 2007;26(19): 3661-75. doi: 10.1002/sim.2832.

36. Benjamini Y, Hochberg Y. Controlling the false discovery rate: a practical and powerful approach to multiple testing. J Royal Stat Soc B. 1995;57(1):289-300.

37. Quanjer PH, Stanojevic S, Cole TJ, Baur X, Hall GL, Culver BH, et al. Multi-ethnic reference values for spirometry for the 3-95-yr age range: the global lung function 2012 equations. Eur Respir $\mathrm{J}$. 2012;40(6):1324-43. doi: 10.1183/09031936.00080312.

38. Stanojevic S, Graham BL, Cooper BG, Thompson BR, Carter KW, Francis RW, et al. Official ERS technical standards: Global Lung Function Initiative reference values for the carbon monoxide transfer factor for Caucasians. Eur Respir J. 2017;50(3):1700010. doi: 10.1183/13993003.00010-2017.

39. Toren K, Schioler L, Brisman J, Malinovschi A, Olin AC, Bergstrom G, et al. Restrictive spirometric pattern and true pulmonary restriction in a general population sample aged 50 - 64 years. BMC Pulm Med. 2020;20(1):55. doi: 10.1186/s12890-020-1096-z.

40. Backman H, Eriksson B, Hedman L, Stridsman C, Jansson SA, Sovijarvi A, et al. Restrictive spirometric pattern in the general adult population: Methods of defining the condition and consequences on prevalence. Respir Med. 2016;120:116-23. doi: 10.1016/j.rme

\section{Tables}

Table 1. Anthropometric and lung function data post mild COVID-19. 


\begin{tabular}{|c|c|c|}
\hline & Males $(n=59)$ & Females $(\mathrm{n}=87)$ \\
\hline Age (yrs) & $\begin{array}{l}50(13) \\
{[28-82]}\end{array}$ & $\begin{array}{l}50(14) \\
{[25-83]}\end{array}$ \\
\hline Weight (kg) & $\begin{array}{c}84.6(15.0) \\
{[61.0-133.0]}\end{array}$ & $\begin{array}{c}70.0(15.3) \\
{[42.0-118.0]}\end{array}$ \\
\hline Height (cm) & $\begin{array}{c}168(8) \\
{[150-182]}\end{array}$ & $\begin{array}{c}153(8) \\
{[137-169]}\end{array}$ \\
\hline Body mass index $\left(\mathrm{kg} / \mathrm{m}^{2}\right)$ & $\begin{array}{c}29.9(4.0) \\
{[22.2-42.0]}\end{array}$ & $\begin{array}{c}30.0(6.2) \\
{[16.6-44.1]}\end{array}$ \\
\hline$\overline{\text { FVC (L) }}$ & $\begin{array}{l}3.97(1.00) \\
{[1.20-6.73]}\end{array}$ & $\begin{array}{l}2.16(0.66) \\
{[1.18-4.51]}\end{array}$ \\
\hline$\overline{F E V}_{1}(\mathrm{~L})$ & $\begin{array}{l}3.26(0.81) \\
{[1.06-5.18]}\end{array}$ & $\begin{array}{l}2.14(0.59) \\
{[0.88-3.75]}\end{array}$ \\
\hline$\overline{F E V}_{1} /$ FVC & $\begin{array}{l}0.82(0.05) \\
{[0.64-0.91]}\end{array}$ & $\begin{array}{l}0.82(0.06) \\
{[0.61-0.95]}\end{array}$ \\
\hline$\overline{\mathrm{PEF}}(\mathrm{L} / \mathrm{s})$ & $\begin{array}{c}9.26(2.15) \\
{[3.29-14.91]}\end{array}$ & $\begin{array}{l}5.75(1.73) \\
{[2.07-9.70]}\end{array}$ \\
\hline $\begin{array}{l}\overline{\text { DLCO }} \\
\left(\mathrm{mL} \cdot \mathrm{min}^{-1} \cdot \mathrm{mmHg}^{-1}\right)\end{array}$ & $\begin{array}{l}26.6(7.7) \\
{[7.6-53.6]}\end{array}$ & $\begin{array}{l}18.7(4.8) \\
{[7.3-30.8]}\end{array}$ \\
\hline$\overline{\text { VA (L) }}$ & $\begin{array}{l}6.03(1.43) \\
{[1.88-9.53]}\end{array}$ & $\begin{array}{l}4.36(0.89) \\
{[1.92-6.25}\end{array}$ \\
\hline $\begin{array}{l}\text { KCO } \\
\mathrm{mL} \cdot \mathrm{min}^{-1} \cdot \mathrm{mmHg}^{-1} \cdot \mathrm{L}^{-1}\end{array}$ & $\begin{array}{l}4.44(0.91) \\
{[2.46-6.84]}\end{array}$ & $\begin{array}{l}4.31(0.84) \\
{[1.71-7.04]}\end{array}$ \\
\hline Altitude of testing (m) & 7 & 7 \\
\hline
\end{tabular}

Data are showed as mean (SD). Brackets represent ranges.

Table 2. Percent predicted for several lung function indices.

\begin{tabular}{lcc}
\hline & Males (n= 59) & Females (n= 87) \\
\hline \% predicted FVC & $91(16)$ & $93(14)$ \\
& {$[31-127]$} & {$[61-131]$} \\
\hline \% predicted FEV $\mathbf{1}$ & $95(17)$ & $90(14)$ \\
& {$[34-124]$} & {$[56-120]$} \\
\hline \% predicted FEV $\mathbf{1} /$ FVC & $104(6)$ & $101(6)$ \\
& {$[83-116]$} & {$[78-116]$} \\
\% predicted PEF & $107(24)$ & $105(28)$ \\
& {$[49-158]$} & {$[53-180]$} \\
\% predicted DLCO & $81(19)$ & $78(17)$ \\
& {$[25-136]$} & {$[39-153]$} \\
\hline
\end{tabular}


Data are showed as mean (SD). Brackets represent ranges.

Table 3. The number and percentage of males and females below the lower limit of normal

\begin{tabular}{cccc}
\hline & Males $(\mathbf{n}=\mathbf{5 9})$ & Females $(\mathbf{n}=\mathbf{8 7})$ & Total $(\mathbf{n}=\mathbf{1 4 6})$ \\
\hline FVC & $15(25 \%)$ & $18(21 \%)$ & $33(23 \%)$
\end{tabular}

$\begin{array}{llll}\text { FEV }_{1} & 11(19 \%) & 14(16 \%) & 25(17 \%)\end{array}$

$\begin{array}{llll}\text { FEV }_{1} / \text { FVC } & 1(2 \%) & 3(3 \%) & 4(3 \%)\end{array}$

\begin{tabular}{llll}
\hline PEF & $6(10 \%)$ & $9(10 \%)$ & $15(10 \%)$
\end{tabular}

\begin{tabular}{llll}
\hline $\mathrm{DLCO}$ & $16(27 \%)$ & $28(32 \%)$ & $44(30 \%)$
\end{tabular}

A Fisher's Exact test was used to compare frequencies between males and females. No statistically significant differences were noted between males and females

Table 4. Variables in the equation to predict impaired DLCO in mild COVID-19 patients ( $\mathrm{n}=$ 144).

95\% CI for odds ratio

\begin{tabular}{llllllll}
\hline Variables & B & S.E. & Wald & $\mathrm{d}_{\mathrm{f}}$ & Sig. & $\begin{array}{l}\text { Odds } \\
\text { ratio }\end{array}$ & lower-upper \\
\hline Age (Z scores) & 0.945 & 0.24 & 15.3 & 1 & 0.000 & 2.57 & 1.60 to 4.13 \\
\hline $\begin{array}{l}\text { Excessive sweating } \\
\text { (yes }=1, \text { no }=0 \text { ) }\end{array}$ & 1.322 & 0.66 & 4.0 & 1 & 0.045 & 3.75 & 1.03 to 13.64 \\
\hline $\begin{array}{l}\text { Blocked nose } \\
(\text { yes }=1, \text { no =0) }\end{array}$ & 1.184 & 0.51 & 5.5 & 1 & 0.019 & 3.27 & 1.21 to 8.80 \\
\hline $\begin{array}{l}\text { Restriction }(1=\text { yes, } 0= \\
\text { no })\end{array}$ & 1.914 & 0.50 & 14.6 & 1 & 0.000 & 6.78 & 2.52 to 18.17 \\
\hline \begin{tabular}{l} 
Constant \\
\hline
\end{tabular} & -2.494 & 0.77 & 10.6 & 1 & 0.01 & 0.08 & \\
\hline
\end{tabular}

Table 5. Variables that predict the proportion of patients who had previous COVID-19 disease with an impaired DLCO at follow-up. 


\begin{tabular}{llcccccc}
\hline & \multicolumn{2}{c}{$\begin{array}{l}\text { Unstandardized } \\
\text { Coefficients }\end{array}$} & $\begin{array}{c}\text { Standardized } \\
\text { coefficients }\end{array}$ & \multicolumn{3}{c}{$\begin{array}{l}\text { 95\% CI for } \\
\text { odds ratio }\end{array}$} \\
\hline Variables & B & S.E. & B & t & Sig. & $\begin{array}{l}\text { Lower } \\
\text { bound }\end{array}$ & $\begin{array}{l}\text { Upper- } \\
\text { bound }\end{array}$ \\
\hline $\begin{array}{l}\text { History of previous } \\
\text { mild vs severe COVID- } \\
19\end{array}$ & 19.9 & 5.8 & 0.45 & 2.78 & 0.002 & 8.1 & 31.7 \\
\hline $\begin{array}{l}\text { Mean age (yrs.) } \\
\text { Criteria to define }\end{array}$ & 1.04 & 0.4 & 0.39 & 2.59 & 0.014 & 0.2 & 1.9 \\
\hline $\begin{array}{l}\text { impaired DLCO } \\
\text { Constant }\end{array}$ & 11.5 & 5.7 & 0.26 & 2.01 & 0.053 & -0.2 & 23.1 \\
\hline
\end{tabular}

Where mild COVID-19 = 0; Severe COVID-19 = 1 ; impaired DLCO defined by DLCO < LLN $=0$; DLCO defined by being less than $80 \%$ of predicted $=1$. Standard error of the estimate $=17.6 \%$.

\section{Supplementary Files}

This is a list of supplementary files associated with this preprint. Click to download.

- ONLINESUPPLEMENTMildCOVID19RespiratoryResearch.docx 